\title{
CULTURA E CURRÍCULO MURA:
} enlace articulador na implementação da escola indígena de São Félix-Autazes/AM

\author{
Jaspe Valle Neto
}

Resumo

A abordagem sobre Educação Escolar Mura não pode ser realizada sem antes relacioná-la à concepção e compreensão do conceito de cultura, requerendo essa explicação como prioridade aos processos do planejamento pedagógico e à organização e elaboração da proposta curricular da escola indígena. O objetivo principal do texto foi analisar de que modo o currículo produzido na Escola Municipal Indígena Dr. Jacobina, localizada na aldeia São Félix-Autazes/Amazonas (AM) se articula com os elementos da cultura do povo Mura. Metodologicamente o texto fundamenta-se na pesquisa qualitativa e procurou seguir as orientações previstas no método hermenêutico-dialético. Os resultados apontam que o currículo que orienta as práticas pedagógicas nesta escola fortalece a identidade e cultura desse povo, pois articula formas de viver/conviver e concebe a escola indígena como palco que viabiliza o trabalho educacional relacionando aldeia/povo/cultura/vida.

Palavras-chave: educação escolar mura; currículo mura; cultura; práticas pedagógicas.

CULTURE AND CURRICULUM MURA: an articulating link in the implementation of the indigenous school São FélixAutazes/AM

\begin{abstract}
The approach about Mura School Education cannot be carried out without first relating it to the conception and understanding of the concept of culture, requiring this explanation as a priority to the processes of pedagogical planning and the organization and elaboration of the curricular proposal of the indigenous school. The main objective of the text was to analyze how the curriculum produced at the Dr. Jacobina Indigenous Municipal School, located in village São Félix-Autazes/Amazonas (AM), articulates with the elements of the culture of the Mura people. Methodologically the text is based on qualitative research and sought to follow the guidelines provided by the hermeneutic-dialectic method. The results show that the curriculum that guides the pedagogical practices in this school strengthens the identity and culture of this people, since it articulates ways of living/coexisting and devises the indigenous school as a stage that enables the educational work engaging village/people/culture/life.
\end{abstract}

Keyword: mura school education; mura curriculum; culture; pedagogical practices.

CULTURA Y CURRICULUM MURA: enlace articulado en la implementación de la escuela indígena São FélixAutazes/AM

Resumen

El enfoque de la Educación Escolar de Mura no puede llevarse a cabo sin primero relacionarlo con la concepción y comprensión del concepto de cultura, lo que requiere esta explicación como una prioridad para los procesos de planificación pedagógica y la organización y elaboración de la propuesta curricular de la escuela indígena. El objetivo principal del texto era analizar cómo el plan de estudios producido en la Escuela Municipal Indígena Dr. Jacobina, ubicada en el pueblo de São Félix-Autazes/Amazonas (AM), se articula con los elementos de la cultura de la gente de Mura. Metodológicamente, el texto se basa en 
investigaciones cualitativas y busca seguir las pautas proporcionadas por el método hermenéutico-dialéctico. Los resultados muestran que el plan de estudios que guía las prácticas pedagógicas en esta escuela fortalece la identidad y la cultura de esta gente, ya que articula formas de vida/convivencia y concibe la escuela indígena como una etapa que permite el trabajo educativo que relaciona al pueblo/gente cultura/vida.

Palabras clave: educação escolar Mura; curriculun mura; cultura; practicas pedagógicas.

\section{INTRODUÇÃO}

O texto é uma produção científica oriunda dos resultados de uma pesquisa de doutorado vinculada ao Programa de Pós-Graduação em Educação da Universidade Federal do Amazonas (PPGE-UFAM), desenvolvida entre 2016-2020, intitulada Currículo da escola e cultura do povo Mura, pesquisa que foi submetida e aprovada pelo Comitê de Ética da Universidade. Os Mura são um povo indígena constituído de 8.487 (oito mil quatrocentos e oitenta e sete) indivíduos, organizados em vinte e quatro aldeias localizadas no município amazonense de Autazes. Segundo Fernandes (2009), os Mura têm sua existência registrada desde 1714.

Tratou-se de uma pesquisa com propósito de investigar como está sendo organizado e implementado o currículo da escola Mura no município de Autazes-AM ${ }^{1}$, trazendo como representatividade dessa escola a instituição de ensino Mura localizada na aldeia São Félix, batizada em 1992 como Escola Municipal Indígena Dr. Jacobina². Portanto, o recorte em estudo da investigação procurou analisar de que modo o currículo produzido nessa escola se articula com os elementos da cultura do povo Mura.

Quanto ao marco metodológico, o estudo se fundamentou na pesquisa qualitativa, com a qual procuramos realizar uma abordagem referente aos fenômenos sociais relacionados ao tempo, local e cultura, e ainda buscamos seguir as orientações previstas no método hermenêutico-dialético. Seguindo essa lógica, Minayo (1992) observa que uma pesquisa fundamentada nesse método deve levar em consideração os aspectos socioculturais, econômicos, os movimentos históricos e as contradições. Foi nessa direção que sistematizamos estratégias metodológicas para recolher e produzir os dados, haja vista que esses dados não estavam prontos e disponíveis, o que nos mobilizou a refletir sobre o contexto da investigação e quais instrumentos deveriam ser elaborados a fim de recolher as informações para posterior organização e análise.

A organização dos dados produzidos gerou categorias de análise que se fazem presentes na composição dos dois tópicos sequenciais discutidos no texto, em que efetivamos a realização dessas análises atendendo ao objetivo proposto. Isso permitiu a adoção de uma postura científica rigorosa, a fim de dar as devidas explicações, visando à compreensão da realidade e totalidade dos fatos apresentados, os quais foram constituídos dialeticamente e qualitativamente.

O recorte da pesquisa que sintetizou este estudo contou com a participação dos seguintes sujeitos mura: o Tuxaua (chefe) da aldeia; o gestor da escola; o secretário da escola; o presidente da Organização dos Professores Indígenas Mura (OPIM); uma mãe de estudante; e os seguintes docentes (entre os 14 docentes atuantes na escola), cuja participação está articulada à temática aqui desenvolvida: professor-1, professora-3, professor-6, professora-7, professora-8, professora-9 e professor-10. A participação desses sujeitos se deu mediante relatos orientados por um roteiro de entrevista semiestruturada que procurou conhecer quais os seus posicionamentos sobre a produção curricular constituída na escola Mura de São Félix. Esta participação respaldou-se em Termo de Consentimento Livre e Esclarecido devidamente lido e assinado por todos.

\footnotetext{
${ }^{1}$ As aldeias de Autazes/AM que possuem escolas Mura são as seguintes: Trincheira, Igarapé Açu, Capivara, Paracuúba, Jawari, Iguapenú, Murutinga, Josefa, Cuia e São Félix.

${ }^{2}$ Escola construída pelo poder municipal há mais de 76 anos, com o objetivo de ampliar a colonização dos Mura e descaracterizar suas práticas culturais nativas.
} 
Estruturalmente, o texto encontra-se organizado com este momento introdutório seguido de dois tópicos e das considerações finais. O primeiro trata sobre cultura e de que modo se articula com o currículo Mura, ou seja, procuramos conhecer a partir dos posicionamentos dos sujeitos como a(s) cultura(s) é/são trabalhada(s) pedagogicamente na escola Mura. O segundo teve o intuito de apresentar como está sendo implementado e produzido o currículo mura na instituição de ensino de São Félix. As considerações finais evidenciam que o currículo em desenvolvimento na escola fortalece a cultura e a identidade dos Mura que habitam o local e as aldeias vizinhas, para as quais essa escola oferece o ensino, uma vez que os temas trabalhados dialogam com os anseios, as expectativas e os modos de organização de vida do povo Mura.

Consideramos que as análises e reflexões desenvolvidas no texto trazem contribuições significativas ao arcabouço da cientificidade, particularmente aos estudos que abordam sobre educação escolar indígena brasileira e amazônica e, ainda, principalmente para o povo Mura do município de Autazes-AM, o qual tem a oportunidade de se apropriar do estudo feito e fazer uma avaliação sobre sua escola, visando cada vez mais fortalecê-la como instituição de ensino indígena que garante ao seu povo uma educação fundamentada e expressa na diferença, auxiliando-o na compreensão de sua relevância enquanto grupo étnico diferenciado que está conseguindo implementar um processo educacional escolar de acordo com seus interesses e organização sociocultural.

\section{CULTURA E ARTICULAÇÃO COM O CURRÍCULO MURA}

Os estudos procedentes da antropologia compreendem o homem como objeto de conhecimento e revelam que nós, seres humanos, somos dessemelhantes dos demais seres com os quais desfrutamos de experiências da vida no planeta e esses aprendizados acabam nos determinando saltar desse mundo da natureza (embora sejamos parte dele e muito necessitamos dele para nossa sobrevivência) para um outro mundo - o cultural.

Nesse trilhar da natureza, somos considerados seres biológicos, entretanto nos transformamos na medida em que estabelecemos novas relações ao nos socializarmos e, com isso, passamos a ser considerados indivíduos culturais. Portanto, no sentido antropológico, a cultura passa, necessariamente, pelo âmbito da unidade biológica e da grande diversidade cultural da espécie humana (ROCHA, TOSTA, 2009).

No contexto das ciências sociais, cultura é o aspecto da vida social que se relaciona com a produção do saber, da arte, do folclore e dos costumes, resultando na transmissão e aprendizagens dos conhecimentos culturais de uma geração à outra.

Thomaz (2000, p. 427) se posiciona afirmando que a antropologia compreende a cultura como uma representação de tudo o que é aprendido e partilhado pelos indivíduos de um determinado grupo e que confere uma identidade dentro do grupo ao qual o indivíduo pertence. Acrescenta que cultura não se refere aos fenômenos individuais, pois o indivíduo necessita estar inserido em um grupo social para dar sentido às suas ações culturais, a partir de suas relações com os seus. Nesse sentido, as experiências culturais acontecem mediante o compartilhamento e a interação do indivíduo com seu grupo imediato, conforme observa o autor: "Fenômeno unicamente humano, a cultura se refere à capacidade que os seres humanos têm de dar significado às suas ações e ao mundo que os rodeia [...]. É compartilhada pelos indivíduos de um determinado grupo, não se referindo, pois a um fenômeno individual".

Ao analisarmos os posicionamentos supramencionados, consideramos que cultura é a prática dos procedimentos atitudinais de um determinado grupo, no entanto é dinâmica e está sujeita a transformações, uma vez que, mediante as intervenções e compartilhamento com outros grupos culturais, novas alterações são estabelecidas nas produções e práticas culturais diversas. 
Assim sendo, a cultura não se perpetua e, conforme o passar dos tempos e vínculos estabelecidos com outras sociedades culturais, novas ressignificações e recriações entram em vigor.

Seguindo esse fio condutor de raciocínio, nos é pertinente afirmar que a cultura ao longo da história sofreu inúmeros processos metamórficos. Traços se perderam e outros se adicionam nas diferentes sociedades culturais. E essas transformações acontecem mediante o confronto com a resistência, como também através das trocas e experiências interculturais, e isso pode representar uma vantagem quando tais modificações são julgadas proveitosas ao grupo atingido, evitando o esforço da sociedade em aceitar ou rejeitar um novo conceito e uma nova prática cultural.

Para Hall (1997, p. 1), a cultura se relaciona com as ações sociais que resultam em significação que possibilitam dar sentido às pessoas que praticam essas ações, como também àquelas que observam. Essa significação encontra-se intrinsecamente ligada às teias dos "[...] sistemas de significados que os seres humanos utilizam para definir o que significam as coisas e para codificar, organizar e regular sua conduta uns em relação a outros. [...] Tomados em seu conjunto, eles constituem nossas 'culturas"'. Nessa lógica, o autor assegura que as práticas sociais se convertem em ações de significação, portanto são culturais.

Estabelecendo relação entre cultura e educação, é inegável que a educação é o caminho e veículo para se atingir a aprendizagem do legado cultural. Através dela as produções culturais são compartilhadas, apreendidas, aprendidas, significadas, ressignificadas, praticadas e reproduzidas. No entanto, é importante a observância que a educação enquanto prática das aprendizagens humanas essencialmente é elemento da cultura, uma vez que essa última agrega tudo aquilo que é produzido pelo homem social.

Nunes (s. d.) analisa que por muito tempo as práticas educacionais hegemônicas consideraram somente a cultura unilateral e homogênea, desconsiderando a pluralidade e a diversidade em suas múltiplas formas de organização de vida social. Somente tinha cultura quem tivesse acesso aos mais dotados e considerados "bens" humanos, negando a existência do verdadeiro sentido de cultura e, principalmente estigmatizando e eliminando a riqueza cultural produzida por grupos minoritários. Nessa condição discriminadora e etnocêntrica, a educação escolar transmitia valores dos grupos sociais dominantes, e com isso disseminava e fortalecia práticas de superação das culturas dos grupos subalternos, como observa a autora:

Por muito tempo a cultura fora vista como única e universal, transformando-se num conceito totalizante, referindo-se ao conjunto de tudo aquilo que de "melhor" havia sido produzido em termos materiais, artísticos, filosóficos, científicos e literários, onde caberia à escola transmiti-los. Essa incumbência dada à escola atribuiu-lhe um caráter homogeneizante e normativo, onde a diversidade deveria ser padronizada, segundo os moldes da então cultura hegemônica (NUNES, s. d., p. 3).

Moreira e Candau (2003, p. 157) ressaltam que embora mudanças significativas tenham ocorrido a partir da reorganização das políticas brasileiras firmadas na democracia, o atual momento ainda é desafiador à escola, para conseguir implementar um currículo que oriente sobre o multiculturalismo existente no contexto escolar e que identifique diferentes culturas presentes em seu cotidiano e que ainda "[...] se assente na tensão dinâmica e complexa entre políticas da igualdade e políticas da diferença".

O posicionamento dos autores acima citados é reforçado pelo pensamento reflexivo de Santos (2003, p. 33) quando afirma que: "[...] as versões emancipatórias do multiculturalismo baseiam-se no reconhecimento da diferença e do direito à diferença e da coexistência ou construção de uma vida em comum além de diferenças de vários tipos".

Diante disso, é dever da escola contemporânea assumir uma postura reflexiva que culmine em relativização, chegando à conclusão sobre a imprescindível importância da diversidade cultural 
e, nesse cenário, procurar “[...] romper com práticas educativas padronizadoras e homogeneizantes, visando seguir um caminho que considere cultura, culturas e educação, muitas vezes precisando redefinir tais conceitos" (NUNES, s. d., p. 3).

No contexto da escolarização são produzidos cotidianamente elementos culturais, os quais constituem a identidade cultural da instituição de ensino e refletem-se na formação dos atores envolvidos. No compreender de Sousa e Carvalho (2017, p. 81):

A cultura escolar, enquanto cultura organizacional, tem como base o estudo dos fatores sociais, culturais e psicológicos que influenciam os modos de agir da organização, como um todo, mas também das pessoas em particular. Esses fatores, impregnados de uma cultura que é própria de cada escola ou instituição se diferem de uma organização para outra.

Corroborando esse posicionamento, Libâneo (2004, p. 106) observa que “[...] quando se pensa em modos de organização e administração escolar já aparece junto a preocupação com a cultura escolar, com as expectativas da comunidade". Portanto, a cultura escolar abrange uma amplitude de influências no agir da instituição de ensino e nas atitudes dos sujeitos que dela participam.

Em tempos atuais e no contexto do cenário educacional, a escola - em especial o projeto de escola indígena brasileira, a partir dos preceitos estabelecidos e das orientações previstas na Constituição Federal de 1988 concernentes à organização e implementação da escola específica e diferenciada - passa a assumir a responsabilidade em refletir, analisar, ensinar e educar o verdadeiro sentido e significado da cultura, rompendo com as ideologias ancoradas e fundamentadas em padronizações, estereótipos e modelos estabelecidos por grupos de poder.

Tal responsabilidade e compromisso da escola indígena é útil para que os estudantes indígenas reconheçam e estejam conscientes sobre a existência das diferentes culturas: a cultura como produção humana e transformadora do homem e a cultura como legado de um grupo étnico que organiza os processos advindos dos elementos culturais do cotidiano, os quais são compartilhados comunitariamente e desenvolvidos na vida em aldeia.

Em contrapartida, Sousa e Carvalho (2017) observam que as práticas desenvolvidas nas escolas não indígenas fortalecem as ideologias da cultura dominante, uma vez que elas prestigiam a padronização de atitudes, valores e comportamentos que se ancoram no currículo e nos moldes de gestão e organização da escola.

Essas práticas excludentes acabam concebendo processos escolares alienadores e que fortalecem as desigualdades sociais. Por isso a justificativa da implementação do projeto da escola indígena específica e diferenciada e com organização própria, uma vez que visa romper "[...] com a padronização da cultura organizacional da escola etnocêntrica, que impõe a padronização de comportamentos, ações e atividades diversas" (SOUSA, CARVALHO, 2017, p. 82).

Sobre esse tema, o gestor Mura da Escola Municipal Indígena Dr. Jacobina ${ }^{3}$, localizada na aldeia São Félix-Autazes/AM, assim se posicionou:

Por muito tempo a escola tirou muito de nós. Principalmente no período longo de colonização e catequização. $O$ que era ensinado nesse período vinha contradizer nossos costumes, nossa cultura. No entanto, a partir da Constituição de 1988, uma nova realidade de escola indígena foi projetada para nosso povo. Agora temos a oportunidade de fazer tudo diferente, pois a escola que violentou a cultura indígena por séculos, agora assume uma nova postura e passa a fortalecer nossa cultura. Isso significa que os valores se inverteram e a escola

${ }^{3}$ A escola Mura de São Félix-Autazes/AM oferece ensino para os estudantes indígenas deste grupo étnico, abrangendo três etapas da educação básica: ensino fundamental I, ensino fundamental II e ensino médio. 
agora passou a ser nossa aliada às nossas lutas pelos nossos direitos e pelo reconhecimento cultural do nosso povo.

Por outro lado, é válido observar que os atuais e múltiplos assuntos que permeiam as atitudes e ações sociais dos diversos sujeitos não escapam da realidade contemporânea do povo Mura de Autazes/AM, configurando também problematizações que precisam ser refletidas, analisadas e pensadas em como proceder e desenvolver a temática cultural dos diversos grupos e de que modo deverá ser inserida no projeto pedagógico e na proposta curricular, haja vista que essa necessidade não pode ser ignorada, considerando que a cultura envolvente processa continuamente novos hábitos e valores que são praticados e vivenciados no mundo globalizado.

Considerando essa questão, é válido enfatizar que nas diversas sociedades não há existência de uma única cultura, mas culturas diferenciadas e que desenvolvem produtos culturais distintos, de acordo com o contexto heterogêneo de cada grupo social. Nesse viés, Sousa e Carvalho (2017, p. 75) assim se posicionam: “[...] Compreender esses distintos elementos, como fenômeno humano e simbologia representativa de determinados povos, de diferentes identidades étnicas, possibilitará a base para desenvolvimento de um currículo intercultural". Vasconcelos (2006, p. 136) reitera que a interculturalidade é "[...] um projeto por construir, uma estratégia, ação e processo permanente de relação e negociação em condições de respeito, legitimidade, simetria, equidade e igualdade".

Essa realidade é destacada pelo atual Presidente da Organização dos Professores Indígenas Mura (OPIM) quando argumenta que os estudantes indígenas precisam também conhecer a cultura do "branco" e foi praticamente eliminado do cenário social. Ele acrescenta que os alunos Mura precisam saber como isso aconteceu, como os colonizadores e os catequizadores se organizaram para eliminar as práticas culturais Mura, pois esses últimos consideravam que somente a cultura deles deveria prevalecer imperiosamente. Ele considerou ainda que a escola Mura de São Félix possibilita também ensinar que existem outras culturas, e que embora não concordem com a organização social de muitas delas, pois tentam o tempo todo ignorar a existência e a cultura indígena, "[...] a gente ensina nossos alunos Mura a respeitar o próximo, e também ensinamos que é importante conhecer as diversas culturas como forma de valorizar a nossa e até mesmo de nos defendermos".

A fala do presidente da OPIM permite inferir que, para além dos conteúdos específicos da cultura Mura de Autazes-AM, que viabilizam processos de aprendizagem, objetivando fortalecer a identidade cultural do povo, na escola também são trabalhados temas relacionados a algumas práticas sociais da sociedade envolvente, as quais de certo modo afetam os costumes culturais dos indígenas de São Félix.

Tal procedimento possibilita desenvolver um intercâmbio intercultural entre os Mura e os povos não indígenas, no sentido de conscientizar os estudantes indígenas de São Félix sobre os modos de organização social desenvolvidos por outras sociedades. Essa prática de conscientização é trabalhada pedagogicamente na escola, visando à obtenção do senso crítico, da ética e da formação cidadã dos estudantes aldeados, os quais terão a possibilidade de avaliar, fazer escolhas e lutar pela autonomia Mura e pela valorização da identidade étnica.

Para Luciano (2008, p. 71), “[...] a interculturalidade não é inverter a relação desigual de discriminado a discriminador, mas uma superação de qualquer forma de simetria nas relações culturais entre indivíduos e sociedades". É nessa perspectiva que a interculturalidade se torna a "[...] proposta mais viável para que, de fato, os processos de ensino e aprendizagens sejam mais significativos para os povos indígenas, rompendo-se com padrões culturais hegemônicos" (SOUSA, CARVALHO, 2017, p. 101).

\footnotetext{
${ }^{4}$ Branco é um termo utilizado pelos indígenas para diferenciá-los das pessoas não indígenas.
} 
Outrossim, destacamos que a grande maioria das populações indígenas do Brasil - exceto aquelas que residem isoladamente nas florestas e que ainda não tiveram contato com a sociedade não indígena - articula relações diretas e indiretas com a sociedade envolvente. Portanto tratam-se de indígenas brasileiros de direito que interagem e integram-se de algum modo à sociedade nacional.

Nesse contexto buscam espaços de participação, mesmo em setores públicos nos quais o diálogo estabelecido é muito mais dissonante e vertical que intercultural, sendo aliás muito mais discursivo que diálogo efetivo e que leve em consideração as diferenças étnicas. No entanto, "[...] a conversa por vezes verticalizada já é uma prática social existente entre os sujeitos portadores de diferentes culturas" (SOUSA, CARVALHO, 2017, p. 101).

Com os Mura essa realidade não é diferente. Eles foram colonizados, catequizados, dizimados, perderam a língua nativa e até hoje ainda são discriminados pela sociedade hegemônica. Isso permitiu que novos costumes e organização de vida fossem transformando suas práticas culturais.

Hoje, muitos elementos culturais se perderam e outros foram adicionados às práticas socioculturais do povo, porém muitas delas ainda estão evidentes, tais como: a caça, a pesca, o cultivo das plantações, a medicina tradicional, comidas típicas, danças, artesanato, etc., embora possam ter sofrido alterações quanto às práticas dos primeiros Mura (PPP-MURA, 2003).

A educação intercultural dos Mura apresenta uma proposta pedagógica que trabalha o conhecimento sobre sua história, vivências, experiências, valores, tradições, expectativas, organização social e cultural, bem como os elementos que compõem as diversas culturas e que se incorporam e migram-se às práticas do dia a dia e na vida social desse povo. Portanto, as práticas educacionais do povo Mura de São Félix

[...]são diferentes, e por isso sua escola será diferente. Isso significa que o sistema educacional de uma sociedade está subordinado aos interesses gerais dessa comunidade. Em outras palavras, a educação faz parte das políticas que cada sociedade adota, buscando a sua sobrevivência e a continuidade das coisas que ela valoriza e em que acredita (por exemplo, sua língua, sua música, sua religião, etc.) (D'ANGELIS, 2012, p. 86).

É nesse prisma que a escola de São Félix vem desenvolvendo a educação escolar para seus estudantes. Nessa direção, o currículo da escola Mura se constrói a partir das necessidades de vida que os moradores identificam coletivamente (professores, pais, equipe técnica, alunos, lideranças da aldeia e moradores da comunidade) e estas convertem-se em temas geradores que são articulados aos conteúdos dos diversos componentes curriculares e trabalhados pedagogicamente em sala de aula. Isso pode ser confirmado a partir dos posicionamentos de diferentes sujeitos, quando defendem este modelo de escola como "ideal" para o povo Mura de Autazes-AM.

O Tuxaua da aldeia afirmou ser muito importante a forma como os professores e a direção da escola conduzem as aulas para os alunos mura. De acordo com ele, a escola reúne com todos: pais, filhos, locatários, lideranças da comunidade, os próprios alunos. Todos participam de discussões em que, no final, são apresentadas as necessidades, os problemas e também aquilo que está dando certo em São Félix: "A partir do resultado da conversa feita com nossos parentes, os professores organizam suas aulas e o ensino é praticado para dar conta das decisões tomadas".

O locatário- $1^{5}$ afirmou que também participa dando sugestões aos temas relacionados com a cultura do povo Mura e que são ensinados na escola indígena de São Félix. Segundo ele, o gestor

5Locatário é o termo dado ao responsável pelos transportes (fluvial: barco; e terrestre: micro-ônibus) que fazem o translado dos estudantes Mura matriculados na escola de São Félix e que moram em três comunidades vizinhas dessa aldeia: Ponta das Pedras, Moray e Natal. 
da escola faz a convocação e juntos com lideranças e comunitários, alunos, pais, professores, secretário e os outros dois locatários dão as devidas sugestões sobre o que deve ser ensinado para os alunos: "Eu acho que é uma forma diferente de trabalhar a educação das escolas do "branco", pois aqui os assuntos das aulas são sugeridos por todos, e tudo isso é trabalhado na escola".

Uma mãe de estudante relatou gostar muito que seus filhos estudem na escola. Para ela, lá eles aprendem sobre a cultura do povo Mura e são conscientizados sobre o que eles devem valorizar: "[...] nossa escola nos ajuda a defender nosso povo e nossos filhos aprendem que eles devem defender nossas terras. Sou muito feliz pela nossa escola, pois os professores também são Mura e ensinam aquilo que vai ser útil para nossa comunidade".

O secretário da escola falou que, por muito tempo, principalmente quando a instituição de ensino estava sob responsabilidade do Serviço de Proteção ao Índio (SPI) e da Fundação Nacional do Índio (FUNAI), ela ensinou a cultura dos "brancos" e os professores não eram indígenas: "Agora, não! A realidade é diferente! Agora todos os professores, todo mundo que trabalha na escola é Mura. Isso é muito bom para o nosso povo, pois a escola tem ensinado sobre nossos costumes, nossa vida em comunidade".

Conforme observamos, as falas acima enunciam que o planejamento curricular da escola de São Félix é desenvolvido com base nas discussões coletivas organizadas pela gestão e professores com participação da comunidade. Os conteúdos são concebidos a partir dos apontamentos feitos pelo povo e estes apresentam como proposta principal o ensino sobre a cultura dos Mura, a importância da aldeia e sua realidade, a história dos povos indígenas, a valorização da identidade étnica e as relações com outros grupos sociais.

\section{CURRÍCULO ESCOLAR E ARTICULAÇÃO COM AS PRÁTICAS PEDAGÓGICAS NA ALDEIA}

No sentido etimológico, o termo currículo vem do latim e possui o significado de "pista de corrida" (CANEN, MOREIRA, 2008). Em termos mais genéricos, o currículo é compreendido como histórico escolar, histórico profissional ou até mesmo história de vida. No contexto educacional, ele é comumente visto como assunto que vai ser ensinado de um determinado componente curricular ou de uma área de conhecimento. Nessa lógica, é batizado como matriz curricular ou programa de conteúdo de um curso de formação.

Para os sistemas públicos ou privados brasileiros, a organização pedagógica segue propostas curriculares oficiais elaboradas por especialistas com aval do Conselho Nacional de Secretários de Educação (CONSED), como os Parâmetros Curriculares Nacionais (PCNs), as Diretrizes Curriculares Nacionais (DCNs), os Referenciais Curriculares Nacionais (RCNs), a Base Nacional Comum Curricular (BNCC) e, no caso do estado do Amazonas, atualmente encontra-se em processo de implementação o Referencial Curricular Amazonense (RCA).

No caso da escola indígena, firmado nos preceitos estabelecidos pela atual Constituição Federal, temos o Referencial Curricular Nacional para Educação Indígena/RCNEI (BRASIL, 1998) que é a principal diretriz orientadora das práticas pedagógicas. Todas essas definições que se articulam ao currículo acabam compreendendo-o "[...] num sentido restrito, pois de fato, currículo, num sentido amplo requer uma conceituação bem mais abrangente" (SOUSA, CARVALHO, 2017, p. 114-115).

Segundo Canen e Moreira (2008), currículo escolar é uma proposta que organiza, reorganiza e norteia todas as ações educativas que envolvem uma escola, sejam elas no âmbito pedagógico propriamente dito, ou no que se refere às inter-relações de todos os envolvidos no processo e ainda em todos os processos envolvidos e desenvolvidos pela escola. 
Kramer (1999, p. 54) afirma que currículo escolar são: “[...] diretrizes que uma escola precisa ter para se desenvolver como um todo: conteúdos, habilidades, metodologia, avaliação, objetivos, projetos - a organização de tudo isso".

Andrade (2003, p. 11) apresenta currículo escolar como plano de ação que operacionaliza a proposta pedagógica da escola. Para esse autor:

É ele que explicita a sequência dos conteúdos (quando ensinar), as formas de estruturar e acompanhar as atividades de ensino e de aprendizagem (como ensinar e avaliar a aprendizagem) e as competências e habilidades a serem desenvolvidas (o quê e por que ensinar [...]. Assim, conceituado, o currículo é o elo entre a teoria educacional e a prática escolar (o que realmente ocorre nas salas de aula), o instrumento que articula possibilidades, necessidades, interesses, pretensões e perspectivas da escola, em um conjunto de escolhas, ações, ênfases e omissões.

Nesse sentido, pode-se considerar que currículo é fruto de uma construção social e cultural, pois tudo aquilo que se planeja e desenvolve está intrinsecamente ligado, visando à melhoria da sociedade, com objetivo de formar cidadãos ativos e críticos para as intervenções necessárias na construção de uma sociedade solidária e democrática.

Num sentido mais restrito, a proposta curricular é um dos principais norteadores do trabalho pedagógico da instituição de ensino a ser desenvolvida, atendendo às necessidades da escola e de seus atores, podendo diagnosticar dificuldades/desafios/possibilidades/superações, tanto no aspecto acadêmico quanto no organizacional.

A concepção de currículo trabalhado pedagogicamente na escola Mura de São Félix compreende que os conteúdos a serem ensinados devam estar interligados com os elementos culturais da vida em comunidade. Nesse sentido, a escola ganha a responsabilidade de desenvolver um "currículo em via de vida", focado nos processos de ensino-aprendizagem pautados no bem comum e no fortalecimento da cultura e identidade Mura.

Esse entendimento é analisado por Luciano (2001), ao observar que a atual proposta designada à escola específica e diferenciada se tornou algo imprescindível e tem sido concebida como real necessidade "pós-contato" pelos povos indígenas. Mesmo considerando todos os desafios e entraves registrados em sua trajetória histórica, o projeto atual de escola indígena, nessa ótica, torna a escola o local onde é estabelecida a relação entre conhecimentos tradicionais e novos conhecimentos, o que deverá ser articulado com equilíbrio, preservando os interesses dos aldeados. Para além disso, a Escola de Índios (expressão de MELIÁ, 1979) possibilita informar a seus estudantes sobre as práticas e modos de organização da sociedade envolvente, como afirma Luciano:

[...] facilitando o diálogo intercultural e a construção de relações igualitárias fundamentadas no respeito, reconhecimento e valorização das diferenças culturais - entre os povos indígenas, a sociedade civil e o Estado. [...] Acreditamos que a escola, como instrumento usado durante a história do contato, para descaracterizar e destruir as culturas indígenas possa vir a ser instrumento decisivo na reconstrução e afirmação das identidades (LUCIANO, 2001, p. 119).

No que se refere ao currículo escolar Mura desenvolvido na aldeia São Félix, este aglutina práticas pedagógicas que requerem um olhar abrangente sobre os diversos fatores que compõem os modos de organização de vida do povo, incluindo os elementos "[...] socioculturais, econômicos, crenças religiosas e também as questões geográficas, nos quais se insere a instituição de ensino, sendo todos estes componentes do que se denomina de currículo" (SANTOS, LOPES, 2013, p. 142). 
Isso é possível identificar nas falas sequenciais abaixo apresentadas pelos(as) professores(as), quando confirmam com eloquência que a proposta curricular encaminhada pela Secretaria Municipal de Educação e Cultura de Autazes-AM (SEMEC) é articulada aos elementos culturais do povo Mura e que isso somente é possível mediante a participação ativa e efetiva da comunidade escolar, de lideranças e de aldeados nas discussões que geram propostas principais de ensino-aprendizagem que são trabalhadas nos quatro bimestres do ano letivo.

A professora-9 (atua no ensino fundamental II, componente curricular de ciências) relatou que a SEMEC de Autazes/AM envia a proposta curricular do município para que o gestor e os(as) professores(as) Mura tenham conhecimento. Após, se reúnem, discutem e procuram adaptar esse currículo com ênfase à realidade e à cultura mura, contextualizando sempre com a vida em comunidade. Ademais, ela destacou dois eventos que são organizados após o encerramento de cada bimestre do ano letivo: mostra cultural e a feira de ciências - que são espaços de socialização de conhecimentos oriundos do trabalho desenvolvido em sala de aula. Segundo ela, na mostra cultural os alunos apresentam para toda comunidade tudo aquilo que aprendem, estabelecendo relação com o tema principal que foi escolhido democraticamente. Nesse sentido, ela explica:

Por exemplo, se trabalhamos como tema principal a água, então a mostra cultural
tem que ser voltada para isso; se trabalhamos no outro bimestre as comidas
típicas dos Mura, o evento também tem que apresentar esse tema. Na feira de
ciências, também procuramos relacionar o tema principal do bimestre com os
aspectos científicos, como por exemplo, se nesse bimestre trabalhamos remédios
tradicionais, então a feira apresenta uma diversidade de remédios que foram
desenvolvidos por nós, indígenas. Não somente isso, mas também procuramos
agregar outros temas, como danças, pintura, a plantação da mandioca e os seus
períodos, onde cada turma fica responsável por cada tema a ser apresentado
nesses eventos.

Para a professora- 7 (atua no $4^{\circ}$ ano do ensino fundamental), cada professor, de acordo com sua área de conhecimento, procura articular os conteúdos curriculares com a cultura do povo Mura. Ela reforçou o que já foi dito anteriormente que, antes do início de cada bimestre letivo, ocorrem reuniões coletivas envolvendo lideranças, pais, moradores, gestão, professores, o pessoal que cuida da merenda e da limpeza, o secretário, o vigia, os locatários e os próprios alunos - momentos em que são discutidos os problemas que estão sendo enfrentados na aldeia, como também as coisas que estão dando certo. A partir daí, surgem os temas para serem trabalhados nas aulas de todas as disciplinas e de todas as séries/anos.

O professor-1 (atua no ensino fundamental II e no ensino médio, componente curricular de arte) complementou que, nessa perspectiva, é elaborado o planejamento bimestral para organizar as estratégias de ensino articulando o tema principal escolhido democraticamente para ser trabalhado no bimestre. E a partir daí cada professor (a) elabora seu próprio planejamento e seus planos de aulas individuais, sempre articulando o tema com os assuntos a serem ministrados. De acordo com este docente, quando termina o bimestre: "[...] nós fazemos uma avaliação com todos novamente, para verificar se conseguimos atingir os objetivos com o tema trabalhado. Já aconteceu de darmos continuidade no outro bimestre com o mesmo tema, quando chegamos à conclusão que isso é necessário".

A professora-3 (atua no ensino médio, componente curricular de biologia) destacou ainda que, após o encerramento de cada bimestre, é feita uma avaliação sobre o que se alcançou a partir do projeto de ensino desenvolvido, com fins de identificar possíveis necessidades oriundas do processo, como também analisar se os objetivos foram alcançados. Ela também enfatizou sobre os eventos mostra cultural e feira de ciências que são organizados pelos professores Mura da escola e objetivam apresentar a toda comunidade os resultados obtidos durante o processo ensino- 
aprendizagem, os quais, segundo ela, são fundamentados na educação própria que se concretiza a partir das necessidades apontadas pelo povo Mura.

Para o professor-6 (atua no $5^{\circ}$ ano do ensino fundamental), o currículo em desenvolvimento na escola de São Félix acaba representando a cultura Mura que está sendo trabalhada em sala de aula, pois os(as) professores(as) procuram trabalhar o conhecimento Mura, tendo como laboratório de pesquisa a própria aldeia e o campo de conhecimento é a terra indígena. Além disso, o docente afirmou que, em 2019, os professores se reuniram com os mais velhos da comunidade para que eles relatassem: "[...] o que cada mês representa como fartura, por exemplo: janeiro é período de quê? De peixes? Se for, a gente procura também trabalhar sobre isso nas aulas. Fevereiro é período da mandioca? Aí nós trabalhamos também esse assunto". Segundo ele, para cada mês, os anciãos vão informando aos professores(as) o que é mais produtivo na terra indígena, e os(as) docentes aproveitam esses ensinamentos e repassam aos seus alunos(as) para quando se tornarem adultos(as) "consigam manter vivos esses elementos culturais".

A professora-8 (atua no $3^{\circ}$ ano do ensino fundamental) relatou sobre sete estudantes egressos da escola, os quais através de processo seletivo em 2019, passaram a estudar o curso Tecnológico em Agroecologia no Instituto Federal do Amazonas (IFAM), o que para essa docente é resultado do processo educacional diferenciado ofertado pela escola de São Félix. Nessa ótica, ela argumentou que esse curso é "muito bom", pois ensina a união entre a prática da agricultura e a preservação do meio ambiente, ou seja, ensina o desenvolvimento sustentável: "Um dia esperamos que, quando eles se formarem, eles possam retornar com os conhecimentos adquiridos e contribuam conosco". Ela ressaltou sobre a educação escolar específica e diferenciada que sempre privilegia a realidade do povo Mura, articulando-a com os outros conteúdos das diversas disciplinas.

O professor-10 (atua no ensino médio, componente curricular de sociologia) relatou que, na prática, em cada turma, os(as) professores(as) Mura trabalham sempre com ênfase no fortalecimento da cultura e identidade do povo e de acordo com os modos de organização da vida em aldeia. Como exemplo ele cita que: "[...] se estão ensinando frases que contenham animais que iniciem com a letra "a", então o aluno aprende sobre animais da região que iniciem com a letra "a", como a anta; e não um animal lá da África".

Ele argumentou que os docentes querem que os (as) alunos(as) se formem dotados(as) do conhecimento tradicional de suas raízes, como também querem que eles(as) possam ter a oportunidade de se formarem em futuras lideranças, parteiras, médicos(as), odontólogos(as), advogados(as), tudo isso para que no futuro venham ajudar os aldeados, bem como lutar pelo seu povo. Por fim, esse último docente enfatizou que, mesmo que um dia, quando os(as) estudantes estiverem formados(as) e que devido a algum impedimento eles(as) não retornarem para seu lugar de origem, que eles(as), de algum modo não possam esquecer as raízes étnicas e que possam sempre ajudar o povo Mura.

Analisando as falas dos(as) professores(as) participantes da investigação acima identificados(as), podemos afirmar que o currículo da escola mura encontra-se fortemente incorporado à cultura do povo Mura. Nesse sentido, concordamos com Lima (2011, p. 4) quando observa que a cultura atravessa o currículo e que isso resulta na produção de identidades e num projeto fundamentado naquilo que se quer formar, particularmente na projeção de que tipo de pessoas se quer formar:

Sendo assim, a cultura também atravessa o currículo. O currículo aqui concebido inscreve-se no âmbito das teorias pós-críticas da educação [...]. A concepção póscrítica do currículo significou uma ampliação dos questionamentos a serem considerados ao se problematizar o currículo para além das questões sobre "o que ensinar". Questiona-se em primeiro lugar "o que eles ou elas devem se tornar" com "o que" for ensinado. O currículo está envolvido, antes de tudo, com a produção de identidades, naquilo que somos e naquilo que nos tornamos. 
O currículo também é uma questão de poder, pois, selecionar envolve poder, privilegiar um tipo de saber, destacar um tipo de identidade como sendo a ideal, representar desta ou daquela forma o outro diferente é uma operação de poder. Assim entendido, o currículo não está em um terreno puramente epistemológico, mas envolve disputas políticas em um território contestado.

Nessa perspectiva, o currículo da escola do povo Mura é um instrumento de poder, uma vez que, de modo ativamente operante, privilegia, destaca, representa e disputa por ideais que se encontram relacionados ao projeto de vida do povo Mura. Por esse viés, transcende a listagem de conteúdos e propostas de ensino, pois desenvolve "[...] manifestação nas relações entre acadêmicos e docentes em um contínuo jogo de forças e como estas produzem identidades e diferenças" (LIMA, 2011, p. 4).

\section{CONSIDERAÇÕES FINAIS}

As reflexões e análises feitas no texto procuram atender o objetivo com postura ética, adotando os preceitos que regem a cientificidade e se debruçou em conhecer os modos constituintes e operantes do currículo da escola de São Félix-Autazes/AM, analisando as relações estabelecidas entre a produção curricular e elementos culturais do povo Mura.

Nesse sentido, ficou constatado que a produção curricular da escola é oriunda do fluxo contínuo fundamentado no diálogo coletivo, reunindo lideranças, moradores, equipe técnica e pedagógica, pais, alunos e toda comunidade de São Félix e demais lideranças das aldeias vizinhas para as quais essa escola oferece o ensino. Eles se reúnem e discutem sobre os problemas, como também apresentam em suas narrativas aquilo que está dando certo na aldeia e o resultado dessas discussões se converte em propostas curriculares para serem desenvolvidas nos 04 (quatro) bimestres do ano letivo.

Considerando que os temas principais trabalhados pedagogicamente na escola dialogam estreitamente com as práticas culturais do povo Mura e são articulados com os demais conteúdos dos diversos componentes curriculares, nossas conclusões revelam ideias relacionadas abaixo.

O currículo produzido na escola atende as reais necessidades do povo Mura de São Félix e das aldeias vizinhas para as quais essa escola oferece o ensino. Essas necessidades visam a socializar, apreender, compreender e praticar a cultura Mura e o respeito à diferença. Portanto, o currículo dessa escola, além de organizar efetivamente as práticas pedagógicas articuladas aos interesses do povo, também se converte num projeto de vida, uma vez que as ações desenvolvidas estão intrinsecamente relacionadas com as práticas e os modos de organização social e cultural da comunidade.

Partindo desta inferência, é pertinente recomendar que as comunidades indígenas, em especial a comunidade Mura do município de Autazes/AM, recebam do poder público o devido apoio financeiro para financiar processos de formação específicos indígenas e, a partir dessa ação, consigam fortalecer seus processos pedagógicos, desenvolvendo pesquisas e tendo a oportunidade de elaborar e publicar seu Memorial, como estratégia de valorizar o conhecimento tradicional e seus elementos e manifestações culturais, objetivando registrar suas origens e produção culturais, para que sejam vistos e respeitados pela sociedade não indígena.

Ademais, que possam ser referendados como um povo que se destacou tantos nos aspectos de organização social como também no cenário educacional. Isso favorecerá o entendimento que deva ser referendado aos Mura de Autazes/AM como um exemplo de grupo étnico que através de seu empenho em prol do bem coletivo tem resistido aos interesses políticos e práticas educacionais homogeneizadoras, as quais descaracterizam a cultura indígena e os transformam em sujeitos invisíveis, sem vozes e direitos. 


\section{REFERÊNCIAS}

ANDRADE, Rosa Maria Cales de. O currículo ressignificado. Porto Alegre/Belo Horizonte: Artmed: Rede Pitágoras, 2003.

BRASIL. Ministério da Educação e do Desporto, Secretaria de Educação Fundamental. Referencial Curricular Nacional para as Escolas Indígenas (RCNEI). Brasília: MEC-SEF, 1998.

CANEN, Ana; MOREIRA, Antônio Flavio. Énfases e omissões no curriculo. Campinas: Papirus, 2008. D'ANGELIS, Wilmar da Rocha. Aprisionando sonhos: a educação escolar indígena no Brasil. Campinas, São Paulo: Curt Nimuendajú, 2012.

FERNANDES, Marcio Roberto Lima. Etnicidade e territorialização: um estudo da política indígena mura em Autazes, Amazônia Central. Dissertação de Mestrado, Programa de Pós-Graduação Sociedade e Cultura na Amazônia, Universidade Federal do Amazonas, Manaus, 2009.

HALL, Stuart. A centralidade da cultura: notas sobre as revoluções culturais do nosso tempo. Educação e Realidade. Porto Alegre, n. 2, v. 22, jul./dez. 1997. p. 15-46.

KRAMER, Sonia. Propostas pedagógicas ou curriculares: subsídios para uma leitura crítica. In: MOREIRA, Antônio Flavio Barbosa (org.). Currículo: políticas e práticas. Campinas, São Paulo: Papirus, 1999.

LIBÂNEO, José Carlos. Organização e gestão da escola: teoria e prática. Goiânia: Alternativa, 2004.

LIMA, Sônia Filiú Albuquerque. Identidades/diferenças indígenas nas teias de um currículo universitário. 34ª Reunião da ANPEd. GT 21, 2011.

LUCIANO, Gersem José dos Santos. Desafios para a execução de uma política pública municipal de educação escolar indígena: dois anos de experiências em São Gabriel da Cachoeira/AM. In: SILVA, Aracy Lopes da; FERREIRA, Mariana Kawall Leal (org.). Antropologia, história e educação: a questão indígena e a escola. São Paulo: Global, 2001.

LUCIANO, Gersem José dos Santos. Educação para manejo e domesticação do mundo entre a escola ideal e a escola real: os dilemas da educação escolar indígena no Alto Rio Negro. Tese de Doutorado, Programa de Pós-Graduação em Antropologia Social, Universidade de Brasília, Brasília, 2011.

MELIÁ, Bartolomeu. Educação indígena e alfabetização. São Paulo: Loyola, 1979.

MINAYO, Maria Cecília S. O desafio do conhecimento, pesquisa qualitativa em saúde. São Paulo/Rio de Janeiro: Hucitec: ABRASCO, 1992.

MOREIRA, Antônio Flavio Barbosa; CANDAU, Vera Maria. Educação escolar e cultura(s): construindo caminhos. Revista Brasileira de Educaşão, São Paulo, v. 1, n. 23, p. 156-168, maio/jun./jul./ago. 2003. Disponível em http://www.scielo.br/pdf/rbedu/n23/n23a11.pdf.

NETO, Jaspe Valle. Educaşão escolar indígena Mura: por entre práticas docentes e o projeto políticopedagógico. Dissertação de Mestrado, Programa de Pós-Graduação em Educação da Universidade Federal do Amazonas, UFAM, Manaus/AM, 2013.

NETO, Jaspe Valle. Currículo da escola e cultura do povo Mura. Tese de Doutorado, Programa de PósGraduação em Educação da Universidade Federal do Amazonas, UFAM, Manaus/AM, 2020.

NUNES, Rojane Brum. A cultura em foco: aproximações entre educação e antropologia. s. d.

ROCHA, Gilmar; TOSTA, Sandra. Antropologia e educação. Belo Horizonte: Autêntica, 2009.

SANTOS, Boaventura de Sousa. Reconhecer para libertar. Rio de Janeiro: Civilização Brasileira, 2003.

SANTOS, Hélio Magno Nascimento dos; LOPES, Edineia Tavares. O currículo na educação escolar indígena: uma análise de pesquisas sobre o tema. Revista Fórum Identidades. Itabaiana: Gepiadde, ano 07, v. 14, jul./dez. 2013. 
SEMEC. Secretaria Municipal de Educação e Cultura. Projeto Politico-Pedagógico Mura. Autazes/AM: 2003, 71 p.

SOUSA, Maria Lucimar Jacinto de; CARVALHO, Maria de Lurdes Dias de. Educação escolar indígena: legislação, currículo e organização. Pará de Minas, Minas Gerais: VirtualBooks Editora, 2017.

THOMAZ, Omar Ribeiro. A antropologia e o mundo contemporâneo: cultura e diversidade. In: SILVA, Aracy Lopes da; GRUPIONI, Luis Donisete Benzi (orgs.). A temática indígena na escola: novos subsídios para professores de $1^{\circ}$ e $2^{\circ}$ graus. São Paulo: MEC, UNESCO, 2000.

VASCONCELOS, Corina Fátima Costa. Pedagogia da identidade: interculturalidade e formação dos professores. Tese de Doutorado, Programa de Pós-Graduação em Educação da Universidade Federal do Amazonas, UFAM, Manaus/AM, 2016.

Submetido em maio de 2020

Aprovado em novembro de 2020

\section{Informações do autor}

Jaspe Valle Neto

Doutor em Educação pelo Programa de Pós-Graduação da Faculdade de Educação da Universidade Federal do Amazonas (PPGE-FACED/UFAM).

E-mail: jaspeufam@yahoo.com.br

ORCID: https://orcid.org/0000-0002-5917-2013

Link Lattes: http://lattes.cnpq.br/6838045075656360 